\title{
La (in)suficiencia del derecho: la producción de la verdad en escenarios transicionales ${ }^{* *}$
}

\section{The (In)Sufficiency of the Law: Truth Production in Transitional Scenarios}

RESUMEN

La diferenciación entre verdad judicial y verdad histórica constituye una premisa central para la justicia transicional $y$, aunque esta última está hoy en día en el centro del debate global, la diferencia entre ambos tipos de verdad y el estudio de sus productos no ha recibido suficiente atención. Este trabajo examina las premisas teóricas que sustentan la distinción entre verdad judicial y verdad histórica a partir del estudio de algunos ejemplos que dejan en evidencia la porosidad de tal diferenciación y sugiere que al observar los insumos que alimentan los productos de los dos tipos de verdad las premisas no se sostienen. Por el contrario, muestra que la verdad no tiene un lugar estático de producción en el diseño institucional de las transiciones.

PALABRAS CLAVE

Verdad judicial, verdad histórica, diseño institucional, justicia transicional, distinción, fuentes.

* Abogada y politóloga de la Universidad de los Andes. Especialista en Gestión Pública e Instituciones Administrativas, magíster en Derecho (investigación) con énfasis en derecho constitucional de la Universidad de los Andes y profesora de derecho constitucional en la Universidad El Bosque. Actualmente es estudiante de la maestría en Derechos Humanos del London School of Economics and Political Science y miembro de la Dirección de Políticas y Estrategia de la Fiscalía General de la Nación.Correo: a.munoz-rincon@1se.ac.uk. ORCID: 00000002-3482-2999.

Agradezco a Esteban Restrepo por haber creído en mis ideas y por haber contribuido, de la manera más enriquecedora, a mi formación intelectual. También a Daniela Samur por su apoyo brillante e incondicional.

** Recibido el 2 de abril del 2020, aprobado el 31 de agosto del 2020.

Para citar el artículo: La (in)suficiencia del derecho: la producción de la verdad en escenarios transicionales. En Revista Derecho del Estado, Universidad Externado de Colombia. N. ${ }^{\circ} 48$, enero-abril de 2021, 85-112.

DoI: https://doi.org/10.18601/01229893.n48.04 
ABSTRACT

The radical differentiation between judicial truth and historic truth seems to constitute a central premise in transitional justice, and although the discussions regarding transitions are now at the center of current global debates, scarce attention has been paid to the actual difference between these two types of truth and their products. This article examines the theoretical premises that support the distinction by means of some examples that serve as proof of its porosity. I suggest that these premises do not hold true when the inputs that go into judicial and historic truth products are observed closely. On the contrary, I show that truth does not have a static place of production in the institutional architecture of transitions.

\section{KEYWORDS}

Judicial truth, historic truth, institutional design, transitional justice, distinctions, sources.

\section{SUMARIO}

I. La insuficiencia de lo jurídico. II. La distinción entre verdad judicial y verdad histórica basada en la insuficiencia del derecho. III. La norma de justicia transicional como expresión de la división. A. El giro punitivo de los derechos humanos. B. Las comisiones de la verdad: elemento del catálogo internacional. IV. Una mirada a las fuentes: cuestionando las premisas de la división. A. La Corte IDH, la CIDH y la Corte Constitucional de Colombia. B. Informes sobre Justicia y Paz del Centro Nacional de Memoria Histórica (CNMH). C. El Acuerdo Final para la Terminación del Conflicto y la Construcción de una Paz Estable y Duradera y el Sistema Integral de Verdad, Justicia, Reparación y No Repetición. Conclusiones. Bibliografía

Francisco de Roux afirma, en La audacia de la paz imperfecta, que "la CEV [Comisión para el Esclarecimiento de la Verdad, la Convivencia y la No Repetición] se hace con la intención de llegar a la verdad humana, que es distinta de la verdad jurídica" ${ }^{1}$. Los escenarios de transición desafían esta premisa-tan ampliamente aceptada- pues solo en ellos confluyen diferentes instituciones con vocación de "descubrir" la verdad de lo ocurrido en el pasado, lo cual difumina las fronteras entre la una y la otra. Esto no sucede en los escenarios ordinarios, en donde la tarea de esclarecer lo ocurrido -el lugar de la verdad-

1 De Roux, F. La audacia de la paz imperfecta, Bogotá: Planeta, 2018, 195. 
le corresponde principalmente a la justicia. Este artículo examina las premisas teóricas que sustentan la distinción entre verdad judicial y verdad histórica -tan propia de la transición- a partir del examen de algunos ejemplos que dejan en evidencia la artificialidad de tal diferenciación. Los productos de la Corte Constitucional, del sistema interamericano de derechos humanos, del Centro Nacional de Memoria Histórica y del Sistema Integral de Verdad, Justicia, Reparación y No Repetición ilustran el argumento central: las premisas que sustentan la diferenciación absoluta entre verdad judicial y verdad histórica no se sostienen cuando se observan de cerca los insumos que los alimentan. Esto resulta en que la verdad transicional, a diferencia de lo que sucede en los escenarios ordinarios, no tenga un lugar estático de producción, sino que circule por todas las estaciones de la arquitectura institucional. Tanto en la literatura ortodoxa como en la crítica, la verdad histórica y la verdad judicial aparecen siempre como dos verdades diferentes y diferenciables que responden a lógicas, objetivos y fuentes diversos ${ }^{2}$.

Este ejercicio tiene un valor teórico y una consecuencia práctica. En términos teóricos busca intervenir en la literatura crítica sobre justicia transicional, al proponer la pregunta por la pertinencia de la distinción absoluta entre verdad judicial y verdad histórica. Esto es fundamental porque contribuye a la discusión sobre la capacidad de lo jurídico para capturar y representar los fenómenos humanos de atrocidad. Así, muestra que el cargo de insuficiencia formulado al derecho en materia de representatividad parece no sostenerse al examinar de cerca las fuentes que sustentan ambos tipos de verdad, toda vez que los productos de verdad histórica están alimentados, en muchas ocasiones, por insumos judiciales. Además, al hacer evidente que las responsabilidades penales se pueden atribuir con base -no exclusiva- en fuentes de verdad histórica, este trabajo también pretende aportar a las discusiones sobre la autoridad del derecho. Finalmente, la reconstrucción sobre los antecedentes de la "teoría de la complementariedad" en materia de diseño institucional de las transiciones también contribuye a identificar cuáles son los fundamentos teóricos detrás de los diseños institucionales aceptados por el marco jurídico internacional para buscar la verdad. Todo lo anterior tiene una consecuencia práctica: al identificar las premisas teóricas que soportan los diseños institucionales, es posible cuestionarlas y reflexionar sobre la manera en que construimos la arquitectura institucional de las sociedades en transición. El propósito de este artículo no es hacer una propuesta normativa, sino señalar las condiciones de posibilidad de las transiciones desde la dimensión teórica.

2 Se considera la literatura crítica el conjunto de autores que revisa las condiciones teóricas, prácticas e institucionales de la justicia transicional y sus limitaciones. 


\section{LA INSUFICIENCIA DE LO JURÍDICO}

Saira Mohamed explora la crítica formulada sobre la capacidad del derecho penal para procesar crímenes atroces ${ }^{3}$. Según su argumento, existe una noción de normalidad que pareciera cobijar al "perpetrador de la atrocidad masiva"4 por dos razones: (1) está actuando de la misma manera que muchas otras personas a su alrededor, a diferencia del perpetrador de los crímenes comunes, que está actuando de manera diferente -anormal y desviada- del resto de la sociedad y (2) usualmente se justifica en la aspiración de perseguir objetivos nobles y loables y actuando en nombre del pueblo o con el pretexto de beneficiar a la sociedad.

Esto resulta problemático para los estudiosos del derecho penal internacional, pues sugiere que "lo que esta persona hizo es lo que esperaríamos que una persona normal hiciera en su situación" . En este sentido, la paradoja a la que se refiere Mohamed es que aunque los sistemas penales y sus cortes están estructurados alrededor de un modelo penal que parte de la idea de un criminal que voluntariamente se ha desviado de las normas sociales, los sujetos que persiguen estas cortes no son desviados en el marco de sus propias comunidades $^{6}$. Algunos académicos han sostenido que las bases del derecho penal son incompatibles con la naturaleza de los fenómenos de atrocidad masiva y que, en consecuencia, el derecho penal no está equipado para tramitar este tipo de eventos. La descripción de la paradoja hace evidente que existe una percepción generalizada que afirma la diferencia radical entre la verdad que puede producir el derecho y aquellas producidas en otros foros.

El trabajo de Shoshana Felman sobre los "grandes juicios" también ilustra las limitaciones de lo jurídico para lidiar con eventos atroces. Felman alega que el derecho es profesionalmente ciego con respecto al fenómeno del trauma, aunque sea el vehículo a través del cual se tramitan mayoritariamente los eventos traumáticos. El argumento de Felman recoge la postura de Hannah Arendt sobre la imposibilidad del juicio de representar adecuadamente aquello -el trauma- que no se puede reducir a conceptos legales. Dice Arendt:

Me parece, por la naturaleza del caso, que no tenemos herramientas disponibles excepto aquellas legales con las que tenemos que juzgar y sentenciar algo que no puede ser adecuadamente representado ni por el derecho ni por la política [énfasis propio].

3 Es importante explorar qué está detrás del argumento según el cual la verdad judicial es insuficiente para representar eventos de atrocidad masiva, pues ayuda a entender el afianzamiento de la división.

4 Mohamed, S. Deviance, Aspiration, and the Stories We Tell: Reconciling Mass Atrocity and the Criminal Law, Yale Law Journal, 124, 5, 2015, 1628.

5 Ibíd., 1648.

6 Ibíd., 1648. 
Tanto Mohamed como Felman exponen los argumentos más importantes alrededor de las limitaciones del derecho para representar eventos traumáticos, como aquellos que están en el centro de los procesos de justicia transicional. En lo que sigue expongo cómo este alegato sobre la insuficiencia del derecho -que se materializa en la consolidación de la división entre verdad judicial y verdad histórica- se derrumba al observar las lógicas de construcción de productos de verdad judicial y verdad histórica a raíz de algunos ejemplos concretos.

\section{LA DISTINCIÓN ENTRE VERDAD JUDICIAL Y VERDAD}

HISTÓRICA BASADA EN LA INSUFICIENCIA DEL DERECHO ${ }^{8}$

Las propuestas teóricas de autores que son representativos de la literatura ortodoxa, y de la crítica, en justicia transicional tienen algo en común: la diferenciación entre verdad judicial y verdad histórica está lo suficientemente sustentada, desde el punto de vista teórico, y partiendo siempre del supuesto de la incapacidad de la una para lograr los objetivos de la otra. Pareciera como si todos los autores -además de argumentar que la verdad judicial y la verdad histórica son efectivamente diferentes- también sugirieran que asî lo deben ser.

El trabajo de Rodrigo Uprimny y María Paula Saffon caracteriza la relación que han tenido la verdad judicial y la verdad histórica a lo largo de los procesos transicionales del último siglo9. Los autores defienden la complementariedad de ambos tipos de producción de verdad y proponen que existen límites de la verdad judicial que tienen que ver, principalmente, con la naturaleza del proceso judicial. Para ellos, los potenciales problemas que puede suponer la búsqueda de la verdad a través de mecanismos judiciales se pueden solucionar con la existencia de vehículos extrajudiciales que permitan, mediante la realización de una tarea colectiva, llegar a una verdad integral. Del mismo modo, Catalina Botero y Esteban Restrepo argumentan que los derechos individuales y colectivos a la verdad se alimentan de diferentes mecanismos, y explican que la verdad histórica tiende a satisfacer de mejor manera la dimensión colectiva del derecho, mientras que la verdad judicial tiende a cumplir con los objetivos

7 ARENDT, H y JASPERS, K. Correspondence 1926-1969, Nueva York: Harcourt Brace Jovanovich, 1992, 417.

8 Con esto se quiere decir que esta premisa desempeña un papel importante para fundamentar la necesidad de dividir ambos tipos de verdad. El reclamo de las víctimas por hacer parte de los procesos de justicia transicional ha sido central para la consolidación de los mecanismos no judiciales. Sin embargo, este artículo no considera ese aspecto para poder explorar, a profundidad, el papel que el cargo de insuficiencia al derecho ha jugado en ese proceso de consolidación.

9 UPRIMNY, R., y SAFFON, M. Derecho a la verdad: límites y potencialidades de la verdad judicial. En: UpRIMNY YePES, R et al. ¿Justicia transicional sin transición? Verdad, justicia y reparación para Colombia, Bogotá: Ediciones Antropos, 2006, 139-172. 
de la dimensión individual del derecho a la verdad. Como señalan Restrepo y Botero, el derecho a la verdad en su aspecto individual es esencialmente de carácter reparador. Por el contrario, la naturaleza de la dimensión colectiva del derecho a la verdad "se erige en una forma de reconstrucción de la historia, en tanto expresa la manera en que el sistema jurídico de una determinada sociedad intenta reconstruir el futuro a través del rediseño del pasado y de su relación con éste" ${ }^{10}$. Esto ilumina que, mientras que el derecho a la verdad en su dimensión individual se satisface, principalmente, a través de la verdad judicial, la dimensión colectiva lo hace en el terreno de la verdad histórica.

Los trabajos de Iván Orozco también muestran que la verdad judicial y la verdad histórica se han entendido como esencialmente diferentes. En Sobre los límites de la conciencia humanitaria ${ }^{11}$. Orozco se pregunta por el tipo de verdad producida por organismos extrajudiciales y distingue entre la verdad factual y la verdad moral. Afirma que "la primera se refiere a lo que sucedió, en tanto que la segunda atañe más bien a la cuestión de por qué sucedió y quiénes son los responsables" 12 . La diferencia que propone Orozco, trayendo a colación a Michael Ignatieff, está relacionada con los conceptos de verdad judicial e histórica que describen Uprimny y Saffon, pues la primera existe para establecer oficialmente qué paso, mientras que la segunda, como la verdad moral, funciona para construir un relato que permita entender las condiciones de posibilidad de la atrocidad. En Justicia transicional en tiempos del deber de memoria, Orozco reflexiona sobre la manera en que la justicia transicional ha aportado a la producción de verdad en las transiciones. En primer lugar, afirma que la actitud del historiador frente al contexto difiere de la del juez, pues el primero hace uso de los contextos en los que se producen los hechos con el fin de "hacer conjeturas [...] sobre el comportamiento de los individuos", mientras que el segundo busca en ellos "circunstancias atenuantes o eximentes de la responsabilidad individual"13. Esta caracterización sugiere que la verdad judicial busca hechos ciertos en el contexto -al preguntarse qué pasó-, mientras que la verdad histórica busca explorar las razones para el comportamiento - porqué pasó- de los protagonistas del horror. De ahí que sea importante considerar no sólo quién, cómo y en qué contexto lee, sino las fuentes que se usan para buscar estas respuestas.

Los casos explorados por Orozco ilustran el paradigma más amplio según el cual la justicia transicional persigue dos tipos de verdades diferentes, y

10 Restrepo E. y Botero, C. Estándares internacionales y procesos de transición en Colombia. En: Uprimny YePes, R. et al. ¿Justicia transicional sin transición? Verdad, justicia y reparación para Colombia, Bogotá: Ediciones Antropos, 2006, 75.

11 Orozco, I. Sobre los límites de la conciencia humanitaria: dilemas de la paz y la justicia en América Latina, Bogotá: Editorial Temis, 2005.

12 Ibíd., 37.

13 Orozco, I. Justicia transicional en tiempos del deber de memoria, Bogotá: Ediciones Uniandes, 2009, 95. 
construye un andamiaje institucional diseñado para este fin. Ruti Teitel explica que esta configuración institucional responde, históricamente, a las condiciones políticas que rodean las transiciones ${ }^{14}$. Según Teitel, el periodo inmediatamente posterior a la Segunda Guerra Mundial estuvo caracterizado por el protagonismo del modelo de justicia penal internacional para juzgar y castigar a los responsables de las violaciones masivas de derechos humanos. En la "fase I" de la justicia transicional primó la necesidad de establecer responsabilidades a través de juicios penales, que resultaran en castigos ejemplares tanto en el plano doméstico como en el internacional. Por el contrario, los modelos de justicia restaurativa en el marco de las transicionales aparecieron con posterioridad al fin de la Guerra Fría (la fase II), pues estaban asociados a una visión menos universal de la justicia transicional, circunscrita a un proyecto más amplio de reconstrucción democrática y reconfiguración de la identidad nacional. En este contexto se consolidaron las comisiones de la verdad como mecanismos distintos del derecho para "revelar" la verdad. En lo que Teitel llama la "fase III" de la justicia transicional los modelos punitivos y restaurativos se encuentran para sustentar la complementariedad en la búsqueda de la verdad.

Algunos autores, como Catherine Turner ${ }^{15}$, Colm Campbell y Fionnuala Ní Aoláin ${ }^{16}$, señalan que la justicia transicional está construida sobre una serie de "oposiciones binarias" ${ }^{17}$. En este sentido, el antagonismo entre conceptos como paz/guerra, conflicto/reconciliación, reconocimiento/negación y caos/imperio de la ley ha sido central para legitimar la creación de un sistema transicional que permita "reemplazar la injusticia con la justicia"18. La oposición entre verdad judicial y verdad histórica hace parte de este marco conceptual, y denota la existencia de una diferenciación radical entre ambos tipos de verdad -una aproximación binaria propia de la justicia transicional-. Las limitaciones inherentes a "buscar" la verdad durante la transición han sido señaladas por la literatura crítica ${ }^{19}$. Erin Daly, por ejemplo, llama la atención sobre la "cascada de la verdad" ${ }^{20}$. Este fenómeno está asociado a la proliferación de las comisiones de la verdad en escenarios transicionales

14 Teitel, R. Transitional Justice Genealogy, Harvard Human Rights Journal, 16, 2015, $69-94$.

15 TuRner, C. Violence, Law and the Impossibility of Transitional Justice. London: Routledge, Taylor \& Francis Group, 2016.

16 Campbell, C and Ní Aoláin, F, The Paradox of Transitions in Liberal Democracies Human Rights Quarterly, 27, 1, 2005, 172-213.

17 Turner, C. Op. cit., 31. Las traducciones de todas las fuentes en inglés son propias.

18 Turner, C. Op. cit., 31.

19 Ní Aoláin, F. y Turner, C. Gender, Truth and Transition, uCla Women's Law Journal, 16, 2007, 229; WeinsteIn, H. Editorial Note: The Myth of Closure, the Illusion of Reconciliation: Final Thoughts on Five Years as Co-Editor-in-Chief, International Journal of Transitional Justice, 6, 2011.

20 DaLy, E. Truth Skepticism: An Inquiry into the Value of Truth in Times of Transition, International Journal of Transitional Justice, 2, 1, 2008, 23. 
que se debe, en parte, a la noción según la cual la verdad histórica contribuye a lograr algunos de los objetivos de la justicia transicional -la sanación de las víctimas, la reconciliación y la demarcación de una clara diferencia entre el pasado y el futuro- mientras que el reconocimiento de responsabilidad pertenece a la esfera de la verdad judicial. Más aún, el debate alrededor de la amnistía a cambio de la verdad en Suráfrica, explorado por Richard Wil$\operatorname{son}^{21}$ y Claire Moon ${ }^{22}$, ilustra igualmente la oposición entre ambos tipos de verdad. El trabajo de ambos muestra que el modelo de justicia transicional surafricano se basó en promover la idea según la cual es imposible encontrar la verdad -y por ende, la reconciliación- a través de los modelos jurídicos retributivos. De hecho, pareciera que hay que "eliminar el derecho" -vía la consolidación de las amnistías- para poder producir un tipo de verdad que sea funcional a la reconciliación. El lema de la Comisión para la Verdad y la Reconciliación, que propendía a la "reconciliación a través de la verdad"23, junto con la concesión de amnistías para todas las violaciones de derechos humanos, ilumina que no es "cualquier" tipo de verdad: es la verdad histórica -no judicial- la condición de posibilidad de la reconciliación. En este orden de ideas, la verdad histórica constituyó la base para la construcción de una "nueva" identidad nacional, profundamente "articulada con cómo responder las violaciones de derechos humanos del pasado" 24 . Lo anterior hace evidente la oposición entre la verdad producida por lo mecanismos judiciales punitivos y aquella que resulta de los procesos extrajudiciales adelantados por una comisión de la verdad, pues únicamente privilegiando la narración extrajudicial de la verdad -y eliminando la judicial-era posible, según el modelo surafricano, reconstruir la nación.

Por otro lado, los trabajos de Elin Skaar ${ }^{25}$ y de Eric Wiebelhaus Brahm ${ }^{26}$ también muestran que la distinción entre verdad histórica y verdad judicial opera como una de las premisas más arraigadas en la literatura sobre justicia transicional. Por un lado, Skaar explica que los mecanismos de verdad extrajudicial priman cuando las dinámicas de poder entre el régimen entrante y el régimen saliente son mas o menos simétrica, mientras que la búsqueda de la verdad por vía judicial responde a la eminente debilidad del régimen anterior y la superioridad, en términos de poder y legitimidad, del nuevo régimen

21 Wilson, R. The Politics of Truth and Reconciliation in South Africa: Legitimising the Post-Apartheid State, Cambridge: Cambridge University Press, 2001.

22 Moon, C. Narrating Political Reconciliation: Truth and Reconciliation in South Africa, Social and Legal Studies, 15, 2, 2006, 257-275.

23 Wilson. Op. cit., 21.

24 Ibíd., 14.

25 SKAAR, E. Truth Commissions, Trials-or Nothing? Policy Options in Democratic Transitions, Third World Quarterly, 20, 6, 1991, 1109-1128.

26 Wiebelhaus Brahm, E. Truth Commissions and Transitional Societies: The Impact on Human Rights and Democracy, London, New York: Routledge, 2010. 
democrático. Esto hace evidente que las verdades producidas por cada uno de estos mecanismos son asumidas como diferentes y, dependiendo de las condiciones políticas, uno u otro tipo puede ser más beneficioso para quienes ostentan el poder. Del mismo modo, el relato histórico de la verdad ha sido entendido como una herramienta que permite -y fomenta- la participación de las víctimas, pues "reconocer oficialmente las versiones de las víctimas puede resultar terapéutico y empoderador" 27 . La afirmación de Wiebelhaus Brahm revela uno de los aspectos más importantes en la diferenciación entre verdad judicial y verdad histórica, pues a esta última -producida por las comisiones de la verdad- se le atribuye usualmente el poder de sanar a las víctimas, a los victimarios y a la nación. Lo anterior ha sido evaluado críticamente por autores como Moon ${ }^{28}$, Stanley Cohen ${ }^{29}$ y Frank Furedi ${ }^{30}$, entre otros, que han documentado los efectos nocivos de la "cultura terapéutica" aplicada a asuntos de la vida política. En particular, Moon explica que las comisiones de la verdad son actualmente consideradas los foros privilegiados para aproximarse terapéuticamente al trauma colectivo, pues sólo la verdad histórica por ellos producida -presumiblemente distinta a aquella que un juicio penal hace posible- permite alcanzar la reconciliación ${ }^{31}$.

La oposición entre verdad judicial y verdad histórica que caracteriza tanto a la literatura ortodoxa como a la crítica se encuentra también en los documentos que consagran las directrices de la Organización de Naciones Unidas (ONU) en materia de justicia transicional. El estudio sobre justicia de transición presentado por el relator especial sobre la promoción de la verdad, la justicia, la reparación y las garantías de no repetición posiciona la verdad histórica como uno de los aportes centrales de la justicia transicional, pues "la justicia penal por sí sola no basta para hacer frente a las atrocidades" ${ }^{32}$. En este sentido, el derecho a la verdad sólo se puede ver satisfecho a través de la combinación institucional de mecanismos judiciales y no judiciales, pues las verdades producidas por ellos son, presuntamente, diferentes. Este es solo un ejemplo de muchos que

27 Ibíd., 4.

28 Moon, C. Healing Past Violence: Traumatic Assumptions and Therapeutic Interventions in War and Reconciliation, Journal of Human Rights, 8, 1, 2009, 71-91.

29 CoHen, S. States of Denial: Knowing About Atrocities and Suffering, Cambridge: Polity Press, 2001.

30 FuREDI, F. Therapy Culture: Cultivating Vulnerability in an Uncertain Age, London: Routledge, 2004.

31 Moon, C. Narrating Political Reconciliation..., op. cit.

32 United Nations (UN), General Assembly, A/HRC/37/65, 6 de junio de 2018. Disponible en https://www.ohchr.org/sp/HRBodies/HRC/RegularSessions/Session37/Pages/ListReports.aspx. Véase también: United Nations (UN), Guidance Note of the Secretary-General. United Nations Approach to Transitional Justice, March 2010. Disponible en: https://www.un.org/ruleoflaw/ files/TJ_Guidance_Note_March_2010Final.pdf; y United Nations (UN), The Rule of Law and Transitional Justice in Conflict and Post-conflict Societies: Report of the Secretary-General, 2004 Disponible en: https://www.un.org/ruleoflaw/blog/document/the-rule-of-law-and-transitionaljustice-in-conflict-and-post-conflict-societies-report-of-the-secretary-general/. 
se pueden encontrar en las posiciones de la comunidad internacional sobre la insuficiencia de la verdad judicial para conseguir los objetivos de la justicia transicional. Todo lo anterior ilustra la posición paradigmática promovida por las instituciones internacionales y aceptada en la literatura crítica y ortodoxa en materia de justicia transicional. La oposición entre la verdad judicial y la verdad histórica se basa en la incapacidad estructural que tiene la verdad judicial, por sí sola, para capturar los fenómenos de atrocidad masiva. Más que evaluar críticamente la formula institucional de las transiciones o sugerir que hay otras mejores, lo pertinente es problematizar uno de sus supuestos más centrales, que hasta ahora se ha aceptado sin mayor discusión: la idea según la cual la verdad histórica y la verdad judicial son radicalmente distintas, nutridas por fuentes diferentes. Si bien la oposición entre ambos tipos de verdad puede estar nutrida por una multiplicidad de factores -como, por ejemplo, la formación disciplinar de quien construye el relato- este artículo se enfoca exclusivamente en explorar cómo la identidad entre las fuentes problematiza la diferenciación absoluta entre una y otra, que hasta ahora se ha asumido como natural.

\section{LA NORMA DE JUSTICIA TRANSICIONAL}

COMO EXPRESIÓN DE LA DIVISIÓN

En esta parte del texto se identifican los fundamentos de la teoría de la complementariedad. Esta teoría -consolidada por la jurisprudencia internacionalaboga por la idoneidad de contar con instituciones judiciales y extrajudiciales de manera simultánea para garantizar el derecho a la verdad. Además, da cuenta de las raíces de los diseños institucionales internacionalmente legítimos hoy en día para las sociedades transicionales y la centralidad del derecho internacional en su determinación.

\section{A. El giro punitivo de los derechos humanos}

La división entre verdad judicial y verdad histórica no solo es relevante para la discusión teórica sobre la capacidad representativa del derecho, sino que también tiene un efecto práctico. La división entre ambos tipos de verdad opera como base para el diseño institucional de las transiciones por mandato del derecho internacional ${ }^{33}$. En este punto es importante recordar los argumentos de Restrepo y Botero sobre la dimensión colectiva y la dimensión individual

33 Véase Corte Interamericana de Derechos Humanos (Corte IDH). Caso Zambrano Vélez y otros vs. Ecuador. Fondo, Reparaciones y Costas. Sentencia del 4 de julio de 2007. Serie C, n. ${ }^{\circ}$ 166, párr. 128; CORTE IDH. Caso Masacres de El Mozote y lugares aledaños vs. El Salvador. Fondo, Reparaciones y Costas. Sentencia del 25 de octubre de 2012. Serie C, n. ${ }^{\circ}$ 252, párr. 298. 
del derecho a la verdad, pues pareciera que esas distinciones teóricas sirvieran para soportar la necesidad de tener simultáneamente mecanismos judiciales y extrajudiciales para la transición.

En el proceso de globalización de la justicia transicional ha surgido una serie de normas y estándares que los Estados deben seguir en los escenarios de transición. Estos catálogos de deberes, que contemplan normas vinculantes y principios rectores, nacieron en el marco del derecho internacional y se entiende que aplican, indistintamente, para todas aquellas sociedades en transición. Sin embargo, la regla según la cual existen unos mínimos para que los Estados aborden las responsabilidades por graves violaciones de derechos humanos se ha posicionado como la más poderosa e imprescindible de todas aquellas directrices que, desde el ámbito internacional, dirigen los procesos transicionales para dotarlos de legitimidad ${ }^{34}$. En este sentido, el discurso del movimiento de los derechos humanos, desde el inicio del siglo XXI, "ha sido casi sinónimo de la lucha en contra de la impunidad" 35 . La "cascada de la justicia" descrita por Kathryn Sikkink se tradujo así en el llamado por castigar la responsabilidad penal individual, indispensable para la legitimidad de los derechos humanos ${ }^{36}$.

La justicia entendida como sinónimo del castigo, y la consolidación de la idea liberal según la cual el derecho y el imperio de la ley son los elementos fundamentales a través de los cuales "ocurre" y "ejerce" el Estado Nación ${ }^{37}$, ofrecen una buena explicación para entender cómo se consolidaron los diseños institucionales vigentes para las transiciones. Bajo las normas actuales del derecho internacional, el establecimiento de tribunales penales durante las transiciones es simplemente imprescindible, pues no tenerlos tendría un costo alto en términos de legitimidad y de responsabilidad internacional. Sin embargo, algunas voces han señalado las limitaciones de los tribunales penales para alcanzar, por sí solos, los objetivos centrales de la justicia transicional $^{38}$. La literatura sobre este asunto es muy amplia, pero para los efectos del presente artículo basta con señalar que es en este contexto en el que se enmarca el advenimiento de las comisiones de la verdad en los escenarios transicionales, como muestra el trabajo de Priscilla Hayner.

34 Subotić, J. Bargaining Justice: A Theory of Transitional Justice Compliance. En: Buckley-Zistel, S. et al, Transitional Justice Theories, Nueva York, Routledge, 2014, 127-143.

35 Engle, K. Anti-Impunity and the Turn to Criminal Law in Human Rights, Cornell Law Review, 100, 5, 2015, 1073.

36 Véase Engle, K. Op. cit., y SiKkinK, K. The Justice Cascade: How Human Rights Prosecutions are Changing World Politics, Nueva York: W.W. Norton, 2013. Véase también: MeISTER, R. After Evil. A Politics of Human Rights, Nueva York: Columbia University Press, 2012.

37 Subotić. Op. cit.

38 Véase McEvoy, K. Beyond Legalism: Towards a Thicker Understanding of Transitional Justice, Journal of Law and Society, 34, 4, 2007, 411-440. 


\section{B. Las comisiones de la verdad: elemento del catálogo internacional}

Las comisiones de la verdad, que son instituciones extrajudiciales características de la justicia transicional, tienen como objetivo reconstruir la verdad con el fin de que la comunidad y, en especial las víctimas, conozcan las condiciones de posibilidad de la atrocidad. Aunque esta descripción pone de presente de manera general el objetivo de los mecanismos extrajudiciales de búsqueda de verdad, Hayner ofrece una definición mucho más robusta:

Una comisión de la verdad: (1) está enfocada en eventos pasados, y no presentes;

(2) investiga un patrón de eventos que sucedió en un periodo de tiempo específico;

(3) trabaja activamente con la población afectada, recogiendo información de sus experiencias; (4) es una institución temporal que tiene el objetivo de concluir con un informe final y (5) está expresamente autorizada/empoderada por el Estado ${ }^{39}$.

La definición que propone Hayner permite inferir la diferenciación radical entre la naturaleza de las comisiones y las cortes judiciales. La autora propone que, aunque la relación entre las comisiones y la justicia criminal se ha caracterizado por ser tensa, la labor de ambos foros debería ser entendida como totalmente diferente e independiente por varios factores. Por un lado, porque las comisiones tienen menos poder que las cortes criminales ya que no pueden obligar a nadie a comparecer o recomendar medidas vinculantes por sí solas. Por otro lado, Hayner afirma que las comisiones de la verdad ni duplican, ni interfieren, ni replican las tareas de los tribunales judiciales en la transición, pues su mandato les permite ir más allá en las investigaciones de lo que sería posible en un juicio criminal. Es evidente entonces que en el esfuerzo por caracterizar la naturaleza de las comisiones de la verdad está presente el alegato sobre la insuficiencia del derecho, que ha sido un argumento recurrente para posicionar la "complementariedad" entre los mecanismos judiciales y extrajudiciales para buscar la verdad. Hay algo que la verdad judicial no puede hacer y que la verdad histórica debe complementar.

Entender a la verdad como un derecho es central para comprender el rol de las comisiones de la verdad, que tiene un lugar casi imprescindible en el diseño institucional de las transiciones a raíz del derecho internacional. El contenido de este ha sido determinado, mayoritariamente, por la jurisprudencia de la Corte Interamericana de Derechos Humanos (Corte IDH) y ha cumplido una labor significativa para aliviar la tensión entre la verdad y la justicia ${ }^{40}$. La jurisprudencia de la Corte IDH analizada en este artículo no corresponde en su totalidad a casos de justicia transicional. Por el contrario, la mayoría trata sobre graves violaciones a los derechos humanos en sede de justicia ordinaria.

39 Hayner, P. Unspeakable Truths, Nueva York: Routledge, 2011, 12.

40 EngLE. Op. cit. 
Pero lo interesante -y sobre lo que poco se ha hablado- es precisamente eso: las obligaciones internacionales que resultan de esas decisiones jurisprudenciales terminan por determinar un modelo de justicia transicional basado en la complementariedad. En este sentido, aunque la jurisprudencia traída a colación no recaiga propiamente sobre casos transicionales, es fundamentalmente relevante para el diseño de la justicia transicional en la actualidad -como muestra el caso colombiano- pues es imposible cumplir con los deberes que resultan de este cuerpo jurisprudencial sin diseñar la transición con base en la complementariedad de mecanismos judiciales y extrajudiciales. Teniendo en cuenta que el propósito de este artículo es interrogar las premisas que soportan la complementariedad, los casos que se estudian en el siguiente capítulo son pertinentes para ilustrar la porosidad de la oposición entre verdad judicial y verdad histórica.

La posición de la Corte IDH ha sido reiterativa al señalar que el derecho a la verdad y el derecho penal están alineados y por eso no es necesario escoger el uno o el otro. Karen Engle explica que la Corte ha tenido tres líneas interpretativas sobre la relación entre verdad y juicios criminales. Según la más reciente, las comisiones de la verdad no pueden cumplir, por sí mismas, con el derecho a la verdad. Al respecto, en La cantuta vs. Perú la Corte IDH afirmó lo siguiente:

La Corte considera pertinente precisar que la "verdad histórica" contenida en ese informe no completa o sustituye la obligación del Estado de establecer la verdad también a través de los procesos judiciales [...] la Corte recuerda que [...] los familiares de las víctimas tienen el derecho, y los Estados la obligación, a que lo sucedido a aquéllas sea efectivamente investigado por las autoridades del Estado ${ }^{41}$.

En esta sentencia, la Corte sienta su posición sobre la naturaleza de las comisiones de la verdad como un mecanismo auxiliar en el entramado de la institucionalidad transicional y revela que el campo de los derechos humanos es de carácter eminentemente penal. La postura de la Corte IDH diferencia de manera tajante las labores que adelanta una comisión de la verdad de aquellas que se encuentran en cabeza de las cortes judiciales. Aunque el componente punitivo es central para la legitimidad de las transiciones, es innegable también que las comisiones de la verdad tienen un lugar fundamental en los diseños institucionales de la transición. En Zambrano Vélez y otros vs Ecuador la Corte afirma que "[1]as verdades históricas que a través de ese mecanismo se logren, no deben ser entendidas como un sustituto del deber del Estado de asegurar la determinación judicial de responsabilidades individuales o estatales por los medios jurisdiccionales correspondientes", en tanto "[s]e

41 Corte idH. Caso La Cantúa vs Perú. Sentencia del 29 de noviembre. Fondo, reparaciones y costas. San José de Costa Rica, 2006, párr. 107. 
trata de determinaciones de la verdad que son complementarias entre sí, pues tienen todas un sentido y alcance propios, así como potencialidades y límites particulares" ${ }^{42}$. Lo que la Corte quiere decir en su jurisprudencia más reciente es que los mecanismos extrajudiciales para la búsqueda de la verdad no pueden reemplazar a los mecanismos judiciales, pero no que se pueda prescindir de estos mecanismos ${ }^{43}$. Aunque la Corte ha sido clara sobre la imposibilidad de que la verdad histórica reemplace la asignación penal de responsabilidades individuales y la búsqueda de la verdad judicial, reconoce que las comisiones de la verdad son un mecanismo de justicia transicional imprescindible para el sistema interamericano de derechos humanos para esclarecer graves violaciones sistemáticas a los derechos humanos ${ }^{44}$.

La creación de una [comisión de la verdad] es un paso fundamental para avanzar en el esclarecimiento de los hechos del pasado. En este sentido [...] desarrollará un rol fundamental en hacer efectivo el derecho a la verdad de las víctimas de violaciones a los derechos humanos cometidas en el pasado, así como de todas las personas y de la sociedad en su conjunto ${ }^{45}$.

Por otro lado, el trabajo de Carsten Stahn muestra que existen consensos internacionalmente aceptados que determinan los mínimos del diseño institucional para las transiciones. Uno de ellos tiene que ver con la necesidad de aproximarse de manera integral a la transición, pues "la justicia del postconflicto requiere de un acercamiento integral para equilibrar una serie de factores interdependientes aunque conflictivos [... ${ }^{\prime 46}$. Aunque hay muchas posibles formas para las comisiones, como señala Hayner, éstas son centrales para el diseño institucional transicional a la luz de estos mínimos internacionales. La legitimidad de las fórmulas que combinan instituciones judiciales y no judiciales para la transición tiene que ver, según Stahn, con la idea de que los juicios criminales son insuficientes toda vez que hay una imposibilidad práctica de llevar a juicio a un alto número de victimarios durante el posconflicto y que, además, la búsqueda de la verdad integral excede sus capacidades. En este sentido, a raíz del consenso internacional sobre el carácter complementario

42 Conte idh. Caso Zambrano Vélez y otros..., op. cit.

43 Comisión Interamericana de Derechos Humanos, El Derecho a la Verdad en América, Washington: OAs in Publication Data, 2014.

44 Véase Corte idh, Caso Zambrano Vélez y otros..., op. cit.; Corte IDH, Caso Gudiel Álvarez y Otros vs. Guatemala. Fondo Reparaciones y Costas. Sentencia del 20 noviembre de 2012 Serie C n. ${ }^{\circ}$ 253, párr. 298, y Comisión Interamericana de Derechos Humanos, Comunicado de Prensa 48/12. Washington: OAS in Publication Data, 2012, 1.

45 Comisión Interamericana de Derechos Humanos, El Derecho, op. cit., 1.

46 STAHN, C. La geometría de la justicia transicional: opciones de diseño institucional. En: RETTBERG, A. Entre el perdón y el paredón: preguntas y dilemas de justicia transicional, Bogotá: Ediciones Uniandes, 2005, 58. 
entre los mecanismos judiciales y los extrajudiciales, las comisiones se han posicionado como instituciones imprescindibles en el diseño transicional.

Con este panorama en mente, es acertado afirmar que el derecho internacional desempeña un papel protagónico en los procesos de justicia transicional domésticos. Aunque se ha establecido que procesos de este tipo son propios de los contextos particulares de cada pasado violento, las instituciones internacionales son actores centrales en los procesos de justicia transicional y el cumplimiento de sus directrices y políticas son determinantes para que gocen de legitimidad. Por ejemplo, la onU señala que son los cuatro pilares del derecho internacional -el derecho penal internacional, el derecho internacional de los derechos humanos, el derecho internacional humanitario y el derecho internacional para refugiados- los principios que deben guiar cualquier proceso de justicia transicional desde el principio ${ }^{47}$. Del mismo modo, la onU afirma que el imperio de la ley -como pilar del sistema internacional- constituye un principio universalmente aplicable que debe ser el objetivo principal de los procesos transicionales. Por lo anterior, el costo de no adoptar las medidas del derecho internacional es alto y le resta legitimidad a cualquier proceso transicional.

En este orden de ideas, los mecanismos judiciales y los extrajudiciales para la búsqueda de verdad, aunque diferentes, son una expresión de la norma internacional de justicia transicional. Aunque el ambiente en el que transcurren las transiciones es altamente punitivo, la creación de mecanismos no judiciales para esclarecer lo sucedido es también fundamental para el proceso. Esto hace evidente lo que sugerí antes: el afianzamiento de la diferenciación entre verdad judicial y verdad histórica constituye la base para el diseño institucional de las transiciones, pues para que la transición sea "completa" se requieren idealmente, según el derecho internacional, instituciones judiciales y no judiciales que se "complementen" entre sí. Este diseño es el más idóneo, según la jurisprudencia de la Corte IDH, para que el Estado pueda cumplir con el deber de satisfacer el derecho a la verdad en todas sus dimensiones.

IV. UNA MIRADA A LAS FUENTES:

CUESTIONANDO LAS PREMISAS DE LA DIVISIÓN

Los procesos de producción de verdad de los tribunales judiciales y de los organismos extrajudiciales en la transición muestran que en muchos casos la verdad judicial es fuente para la construcción de la verdad histórica, y viceversa. Para cuestionar la "pureza" de la división entre ambos tipos de verdad y complejizar la discusión alrededor de la producción de verdad a través de los diseños institucionales para la transición, es pertinente discutir

47 United Nations (UN), Guidance Note of the Secretary-General, cit., y United Nations (UN), The rule of law and transitional justice, op. cit. 
algunos ejemplos que dan cuenta de la imposibilidad de observar en la práctica aquello que está tan afianzado en la teoría y en el diseño institucional.

\section{A. La Corte IDH, la CIDH y la Corte Constitucional de Colombia}

La verdad histórica como fuente de la verdad judicial se puede observar en algunos pronunciamientos jurisprudenciales de la Corte IDH y en informes de la CIDH. En el informe El derecho a la verdad en América, la Comisión señala:

Tanto la Comisión como la Corte han resaltado la importancia de las [comisiones de la verdad] como un mecanismo extrajudicial de justicia transicional, orientado al esclarecimiento de situaciones de violaciones masivas y sistemáticas de derechos humanos. En ese sentido, en múltiples ocasiones ambos órganos se han valido de la información proporcionada por los informes finales de las [comisiones de la verdad] como fuente de información y elementos de prueba en relación con casos tramitados ante el sistema de casos y peticiones ${ }^{48}$.

El informe, que recoge los lineamientos establecidos por la CIDH en lo relativo al derecho a la verdad, hace evidente que la verdad histórica tiene la capacidad de constituirse como fuente de los procesos judiciales, no solo como información que permite dar inicio al proceso sino también como aquello que permite continuar con la asignación de responsabilidad individual:

El trabajo de las [comisiones de la verdad] constituye una forma de reconocimiento y dignificación de las experiencias de las víctimas y una fuente fundamental de información tanto para el inicio y continuación de procesos judiciales, como para la elaboración de política pública y mecanismos de reparación adecuados ${ }^{49}$.

Más importante aún, la Corte ha reconocido que los informes no solo se pueden constituir como fuente, sino como medio de prueba en los procesos adelantados ante el sistema interamericano de derechos humanos. Un ejemplo claro de esto se puede observar en el caso Chitay Nech y Otros vs. Guatemala, en donde la Corte acepta el informe Guatemala: Memoria del Silencio de la Comisión para el Esclarecimiento Histórico de Guatemala y el informe Guatemala Nunca Más de la Oficina de Derechos Humanos del Arzobispado como medios de prueba para establecer la responsabilidad del estado guatemalteco ${ }^{50}$. Del mismo modo, y más recientemente, en Vásquez Durand y otros vs. Ecuador la Corte afirma que el "Tribunal tomará en cuenta el Informe de la Comisión de la Verdad del Ecuador como un medio de prueba que debe ser valorado junto con el resto

48 Comisión Interamericana de Derechos Humanos. Op. cit. El Derecho..., 61.

49 Ibíd., 84.

50 Véase Corte IDH. Caso Chitay Nech y otros vs. Guatemala. Excepciones Preliminares, Fondo, Reparaciones y Costas. Sentencia del 25 de mayo de 2010, Serie C, n. ${ }^{\circ} 212$. 
del acervo probatorio" ${ }^{51}$. Aunque estos son solo dos ejemplos de las muchas sentencias en las que los informes de verdad histórica se han admitido como medio de prueba, corrobora la presencia determinante de fuentes de verdad histórica en la construcción de la verdad judicial ${ }^{52}$.

Ahora bien: la Comisión y la Corte también han señalado en muchos pronunciamientos la necesidad de que las comisiones de la verdad puedan acceder sin restricciones a la información que necesitan para cumplir sus funciones, incluida la judicial, que es la que normalmente goza de reserva. En José Miguel Gudiel Álvarez y Otros vs. Guatemala, la Corte señaló que

La comisión debe tener acceso pleno a los archivos del período que le corresponde investigar, incluyendo con ello el acceso a la información "secreta" o "reservada" [...] el acceso a dicha información, debe darse en las mismas condiciones que las que garantizan el acceso a los operadores judiciales que investigan violaciones de derechos humanos ${ }^{53}$.

Algo similar sucede en Colombia. La Corte Constitucional, en la sentencia C-017 de 2018 -que hace control automático de constitucionalidad al Decreto 588 de 2018 que organiza la cEv- se pronunció sobre las reglas para el acceso a la información judicial reservada por parte de la CEv:

La Corte declarará la exequibilidad condicionada de la expresión "conforme a lo dispuesto en el artículo 21 de la Ley Estatutaria de Transparencia y del Derecho de Acceso a la Información Pública Nacional no son oponibles las reservas en materia de acceso a la información pública frente a las violaciones de los Derechos Humanos o infracciones al DiH, en el entendido de que, respecto de la CEv, esta inoponibilidad se extiende a todo tipo de información, no solo a la que verse sobre violaciones a los DD. HH. e infracciones al $\mathrm{DIH}^{54}$.

Además, señaló:

No es procedente oponer ningún tipo de limitación, restricción o salvedad a la CEV para acceder a toda clase de información pública [...] en la expresión "reserva alguna" debe entenderse comprendida toda la información respecto de la cual se ha establecido cualquier tipo de restricción a su conocimiento $[\ldots]^{55}$.

51 CoRTe idH. Caso Vásquez Durand y otros vs. Ecuador. Excepciones Preliminares, Fondo, Reparaciones y Costas. Sentencia de 15 de febrero de 2017. Serie C, n. ${ }^{\circ} 332$.

52 Véase Corte idh. Caso Escué Zapata vs. Colombia. Fondo, Reparaciones y Costas. Sentencia del 4 de julio de 2007. Serie C n. ${ }^{\circ}$ 165, párr. 26; Caso De la Masacre de Las Dos Erres vs. Guatemala, supra nota 12, párr. 58.

53 CoRte IDH. Caso José Miguel Gudiel. Op. cit., párr. 464.

54 Corte Constitucional de Colombia. C-017 de 2018. Sentencia del 21 de marzo. Bogotá, 2018, 213.

55 Ibíd. 
Aunque en la sentencia la Corte Constitucional habla de "información pública", la información que goza de la reserva que la Corte prohíbe oponer es, mayoritariamente, aquella de carácter judicial de procesos penales. Adicionalmente, la Corte levanta la reserva de todo tipo de información, incluida la judicial, para que la cEv la pueda conocer sin necesidad de órdenes judiciales de por medio. La posición de la CIDH, de la Corte IDH y de la Corte Constitucional da cuenta de que uno de los insumos principales y fundamentales para la construcción de la verdad histórica son los archivos y expedientes que constituyen la verdad judicial. La información judicial es pues, uno de los primeros insumos necesarios, o mejor, el punto de partida para el ejercicio de las funciones de las instituciones extrajudiciales. Tanto es así que las instituciones judiciales han tenido que abrir el camino para que las comisiones de la verdad puedan acceder a la información judicial, so pena de que el Estado incurra en la violación de derechos establecidos en la Convención Americana de Derechos Humanos y en materia penal y disciplinaria de acuerdo a la legislación local.

\section{B. Informes sobre Justicia y Paz del Centro}

Nacional de Memoria Histórica $(\mathrm{CNMH})^{56}$

El 18 de enero de 1989 un grupo paramilitar masacró a doce funcionarios judiciales que pertenecían a juzgados de instrucción criminal y que estaban en el Magdalena Medio investigando una serie de homicidios y desapariciones. Además de las investigaciones sobre estos hechos, el Colectivo de abogados "José Alvear Restrepo" presentó en 1999 una denuncia ante la CIDH de la que resultó una serie de recomendaciones para el Estado colombiano. En febrero de 2006 la CIDH concluyó que el Estado no había cumplido las recomendaciones y sometió el caso a la jurisdicción de la Corte IDH. En este contexto, el informe del CNMH La Rochela: memorias de un crimen contra la justicia tuvo como objetivo "ventilar la verdad sobre lo sucedido y rescatar del olvido la memoria de este [...] episodio" 57 y fue realizado por el grupo de Memoria Histórica de la Comisión Nacional de Reparación y Reconciliación por mandato expreso de la Corte IDH.

El informe, que resultó de la condena al Estado colombiano, tenía una pretensión reparadora, pues "para tratar de reparar a los vivos, en la medida en que ello es posible, debemos empezar por recordar cada una de las personas de carne y hueso que fueron asesinadas así como a quienes, por un azar que desafía toda lógica, sobrevivieron al horror y lo contaron" ${ }^{58}$. El informe, como

56 Se exploran los informes que se consideran más representativos. Esto no quiere decir que el fenómeno no se pueda observar en otros informes, ni que se pueda observar en todos.

57 Centro Nacional de Memoria Histórica (CNMH). La Rochela: memorias de un crimen contra la justicia, Bogotá: Publicaciones Semana, 2010, 25.

58 Ibíd., 25. 
se advierte en varias partes de él, tiene como fuente primaria el archivo judicial de la investigación penal. Es con base en este archivo, junto con la recopilación de algunos testimonios y notas de prensa, como se intenta reconstruir los hechos en aras de aportar a la construcción de la memoria histórica del conflicto armado en Colombia, como una de las medidas de reparación simbólica para las víctimas. Esto no significa que este sea el modus operandi en todas las iniciativas de verdad histórica, pero el protagonismo del archivo judicial en la construcción de este informe ilumina la discusión que este artículo propone.

En La Rochela se advierte sobre la necesidad de tener claros los hechos y los antecedentes que dieron pie al trabajo investigativo. En este sentido, el capítulo I está dedicado a determinar "quiénes, cómo, cuándo, dónde, motivados por qué y en qué circunstancias precisas mataron a otros" ${ }^{59}$. Esto parece corresponderse con lo que hace un juez en el marco de la actividad judicial, pues buscar las respuestas a estas preguntas es precisamente el objetivo del proceso penal. El capítulo narra los hechos y sus antecedentes de la misma manera en la que se narrarían en una sentencia judicial, no solo por el hecho de tratar de organizar una historia y de dotarla de sentido cronológico, sino también porque parte de la necesidad de aclarar los hechos antes de proceder con su juzgamiento. Esta es una movida propia del derecho, pues el proceso jurídico de "juzgar" deriva su legitimidad, entre otros factores, de haber partido de la reconstrucción objetiva e imparcial de unos hechos que se han establecido como el pilar de la investigación.

En la introducción también hay algunas cosas particulares, pues el informe es reiterativo al afirmar que su objetivo principal es encontrar la verdad para poder construir memoria histórica como herramienta de reparación para las víctimas. Sin embargo, la mayoría del informe se dedica efectivamente a tratar de establecer las condiciones de tiempo, modo y lugar de la ocurrencia de los hechos y formula reflexiones jurídicas, en el capítulo III, sobre la manera en la que se establece la responsabilidad penal en este caso. El informe pretende, principalmente, desentrañar responsabilidades individuales y colectivas mientras que la voz de las víctimas aparece como un anexo secundario al que únicamente se le dedica uno de los capítulos del informe. En este sentido, el informe diferencia dos tareas: el relato objetivo, casi técnico -como el derecho- que ocupa la primera parte del texto y el relato subjetivo, desde la voz de las víctimas, que se hace en el capítulo Iv. De esta manera, aunque el informe nace con la vocación de dignificar la voz de las víctimas, la mayor parte adelanta la misma tarea del derecho: aquella que aclara hechos y atribuye responsabilidades. En la introducción del informe, los investigadores reconocen que el análisis de la primera parte determina hechos, caracteriza lo sucedido y lo analiza a la luz de dispositivos normativos: 
Los primeros tres capítulos, escritos sobre todo en el lenguaje más bien objetivo de la historia crítica y del derecho, se ocupan de la reconstrucción de los hechos de la masacre, de la ruta judicial y de la valoración jurídica del caso, tanto al a luz de las normas vigentes en la época como de las normas vigentes hoy en día ${ }^{60}$.

Ahora bien: el informe Los silencios y los olvidos de la verdad es un análisis sociojurídico del proceso de Justicia y Paz a través de un estudio de caso que tuvo como objetivo "verificar el real aporte de ese proceso al propósito de reconstrucción de la verdad histórica" ${ }^{\circ 1}$. En el texto sucede algo similar a $L a$ Rochela, pero de manera menos evidente, pues el uso mayoritario de las fuentes judiciales no ocurre en todos los capítulos. Sin embargo, los capítulos v y VII están nutridos por fuentes judiciales nacionales e internacionales. En el capítulo III se propone un análisis principalmente normativo sobre los postulados del derecho internacional humanitario (DIH). El capítulo v se dedica en buena parte a reconstruir el análisis de constitucionalidad de la Ley de Justicia y Paz, casi que exclusivamente con base en las sentencias de la Corte Constitucional que ponen de presente cuáles son los conceptos técnicos jurídicos que están en el centro de esta ley, así como algunas estadísticas procesales que resultan del análisis de expedientes. Del mismo modo, el capítulo viI se basa principalmente en las versiones libres contenidas en los expedientes judiciales rendidas por los postulados en esta ley. Aunque este capítulo pretende hacer una crítica al aporte de las versiones libres para la verdad histórica, hay mucho espacio dedicado a la reconstrucción de las declaraciones y audiencias de los postulados que reposan en el expediente. Una sección del capítulo se embarca en una tarea que parece eminentemente jurídica: establecer y comprobar si las acciones del Bloque Magdalena Medio configuran un conflicto armado desestructurado a la luz del DIH. El desarrollo de esta exploración -la de "analizar algunas características del conflicto armado desestructurado para comprobar si en efecto se dio una confrontación que corresponda a esa categorización del DIH" ${ }^{2}$ - se hace casi que siguiendo un ritual procesal probatorio, pues para cada una de las categorías establecidas por el DiH se ofrecen "pruebas" que, en efecto, vienen de las versiones libres contenidas en el archivo judicial ${ }^{63}$. Esto no significa que los informes -o la labor del $\mathrm{CNMH}-$ no sean independientes. Tampoco implica que el deber de "memoria judicial" consagrado en la Ley 975 de 2005 y en la Ley 1592 de 2005 -que requiere de la interacción constante entre el CNMH y los Tribunales Superiores del Distrito Judicial- no sea

60 Ibíd., 27.

61 CNMH. Justicia y Paz: Los silencios y los olvidos de la verdad, Bogotá: Centro de Memoria Histórica, 2014, 39.

62 Ibíd., 461.

63 Las comillas llaman la atención sobre el carácter judicial de "comprobar", pues supone un debate contencioso en el que, vía medios de prueba, se busca convencer sobre la certeza de la ocurrencia de un hecho. 
deseable y propio de un marco normativo transicional. Lo que sí ilumina es que la actividad de producir verdad histórica está fuertemente mediada por las fuentes y los ritos judiciales.

En general, los dos informes ilustran bien dos dimensiones del argumento de este artículo. Dan cuenta de la utilización de fuentes, de lógicas y de formas jurídicas en la elaboración de productos de verdad histórica y, adicionalmente, demuestran que el cargo sobre la insuficiencia del derecho es una de las bases que sustentan la diferenciación verdad judicial y verdad histórica, pues la existencia misma de los informes sugiere que la verdad histórica hace algo distinto de la verdad judicial. Como este artículo muestra, esto no es completamente cierto. De hecho, en el informe sobre Verdad judicial o verdad histórica los autores advierten los "peligros" sobre el uso del archivo judicial para hacer historia, dos actividades presuntamente diferentes, proponiendo algunas precauciones que se deben tomar en la tarea, como:

No sobra recordar que la verdad judicial está construida judicialmente en función de una decisión que compromete las fuerzas legítimas de coerción del Estado [...] la verdad jurídica [...] es inseparable de la decisión judicial [...] en cuanto aparato que produce verdades con fines ejecutivos el aparato judicial está obligado a reafirmar [...] la autoridad tradicional del Estado [...]. De ahí que se pueda decir que todo fallo judicial es un ejercicio de interpretación de la tradición jurídica que legitima el ejercicio de poder por parte del Estado ${ }^{64}$.

Esta advertencia hace evidente que efectivamente quienes hacen memoria histórica parten de la base de que hay algo que el derecho no puede capturar, pues la verdad judicial tiene unas características estructurales que le impiden construir una verdad "completa" y "objetiva". Por esta condición, las limitaciones inherentes al derecho descritas en este informe son una de las premisas que sostienen la división entre la verdad judicial y la verdad histórica y sustentan la complementariedad, como estas páginas han argumentado. Todo esto, además, parece ser fundamental para el diseño institucional basado en la complementariedad.

\section{El Acuerdo Final para la Terminación del Conflicto y la Construcción de una Paz Estable y Duradera y el Sistema Integral de Verdad, Justicia, Reparación y No Repetición}

Por último, es interesante traer a colación el caso particular del Sistema Integral de Verdad, Justicia, Reparación y No Repetición (SIVJRNR), pues su componente judicial -la Jurisdicción Especial para la Paz (JEP)- ha recibido informes de verdad producidos por mecanismos extrajudiciales como insumos para su labor.

64 CNMH. ¿Verdad judicial o verdad histórica? Bogotá: Publicaciones Semana, 2012, 21. 
Hay dos ejemplos concretos de esto. En primer lugar, el mandato a la Sala de Reconocimiento de Verdad y Responsabilidad (SRVR) consagrado en el literal C del numeral 48 del punto 5.1.2 del Acuerdo Final para la Terminación del Conflicto y la Construcción de una Paz Estable y Duradera (AFTC) da cuenta del lugar de la verdad extrajudicial para la producción de la verdad judicial. Establece que los informes de las organizaciones de víctimas y de derechos humanos colombianos servirán como insumo para establecer las conductas que se dieron en el marco del conflicto armado y los responsables de las mismas. El literal H señala la función de los informes:

Una vez recibidos todos los informes establecidos en los apartados b y c describiendo conductas los contrastará, y después de haber tenido en cuenta la versión de que trata el literal (e), en caso de apreciar que existen bases suficientes para entender que la conducta existió, que la persona mencionada participó y que la conducta corresponde a tipos penales no amnistiables, deberá ponerlos a disposición de los presuntos responsables para que por ellos se tome la decisión de comparecer o no comparecer a efectuar reconocimiento de verdad y responsabilidad o comparecer a defenderse de las imputaciones formuladas ${ }^{65}$ [énfasis propio].

Aunque la norma no implica que los informes extrajudiciales puedan ser considerados medios de prueba, sí establece claramente que constituyen el punto de partida para (1) establecer existencias de conductas punibles; (2) determinar al autor o autores de la conducta y (3) formular imputaciones de delitos. Esto hace evidente que la verdad histórica es, efectivamente, fuente formal para la producción de la verdad judicial en la JEP. Además, el artículo muestra que los informes de verdad histórica en este contexto gozan del mismo estatus que los productos de verdad judicial como insumos para la toma de decisiones sobre responsabilidades penales de la mencionada sala y deben ser valorados como tal, mostrando la porosidad de las fronteras entre la verdad judicial y la verdad histórica.

Por otro lado, Gonzalo Sánchez, en calidad de director del CNMH, entregó 80 informes de memoria histórica a la presidenta de la JEP y a la presidenta de la SRVR en julio de 2017. El mandato legal de entregar informes de memoria histórica al componente judicial del sIVJRNR problematiza la oposición entre verdad judicial y verdad histórica. No deja de ser curioso el mandato según el cual una institución dedicada a la producción de verdad extrajudicial debe entregar informes de memoria al componente judicial del sIVJRNR. En el discurso que Sánchez pronunció en la ceremonia de entrega es evidente que la verdad histórica es fuente de la verdad judicial y viceversa:

65 Gobierno de Colombia y Fuerzas Armadas Revolucionarias de Colombia. Acuerdo Final para la Terminación del Conflicto Armado y la Construcción de una Paz Estable y Duradera. Bogotá, Colombia, 2016. 
La documentación judicial, por un lado, se ha convertido en un insumo y en un objeto de análisis importante para la reconstrucción de la memoria histórica, como lo ilustran los informes sobre justicia y paz realizados por el propio сNмн [...].

Por otro lado, los informes de memoria histórica se han convertido a su vez en soporte importante de la acción judicial. De hecho, el cNMH ha producido una serie de informes $[\ldots]$ a solicitud de fiscales $[\ldots]$.

A esto se suma la incorporación en los fallos judiciales en el plano nacional, y en instancias internacionales como la CIDH, de los contenidos de los informes sobre las masacres de Trujillo, Segovia, la Rochela, el Salado, el Placer, etc. $[\ldots]^{66}$ [énfasis propio].

El tono de Sánchez es uno de victoria para la verdad histórica, pues resalta la importancia de que los informes de memoria histórica no solo se hayan constituido como apoyo para la acción judicial, sino el hecho mismo de que se encuentren incorporados en fallos locales e internacionales como si ese fuera su propósito más importante. También reconoce el protagonismo del archivo judicial en el trabajo de los informes del CNMH que se mencionaron previamente. Para cerrar su intervención, afirma:

La verdad histórica y la verdad judicial siguen distintas lógicas y sentidos, se asientan en diferentes metodologías y escenarios, y tienen diferentes protagonistas. La memoria, más que a individualizar, apunta abiertamente a desentrañar responsabilidades estructurales, tramas sociales y políticas, con un sentido que no se restringe a la determinación de los victimarios y de las culpabilidades ${ }^{67}$.

Las afirmaciones que preceden a esta declaración, como el hecho mismo de entregar informes de memoria histórica a un órgano estrictamente judicial parecerían desvirtuar la diferencia de lógicas, sentidos, escenarios y protagonistas entre la verdad judicial y la verdad histórica y confirmar la identidad entre las fuentes de ambos mecanismos de producción de verdad. La interacción entre los mecanismos judiciales y los no judiciales es característica de las transiciones, pues precisamente las aproximaciones transicionales $-\mathrm{a}$ diferencia de las ordinarias- tienden a ser holísticas e integrales ${ }^{68}$. Sin embargo, la posibilidad de que informes de verdad histórica operen como una de las bases para la acción legal -en cualquier nivel- invita a pensar críticamente sobre la oposición entre verdad judicial y verdad histórica, y a cuestionar la tendencia de asumirla como natural. Adicionalmente, la Fiscalía General la

66 SÁnchez, G. La memoria y la justicia. Palabras en entrega de Informes del Centro Nacional de Memoria Histórica (CNMH) a la Jurisdicción Especial para la Paz (JEP), Bogotá, 2017.

67 Ibíd.

68 Conte idh. Caso Zambrano Vélez y otros..., op. cit. 
Nación ha establecido direcciones dedicadas a analizar e identificar responsabilidades estructurales a raíz del estudio del contexto social y político en el que se enmarcan los patrones de criminalidad. De esta manera, aunque los dispositivos del derecho penal busquen determinar responsabilidades individuales, también buscan establecer estructuras y patrones de fenómenos criminales que ayuden a entender eventos integralmente. Así, no solamente la memoria realiza esta tarea.

Todos estos elementos sirven para ilustrar el argumento de este texto según el cual la oposición entre verdad judicial y verdad histórica es porosa, y en muchos casos artificial, en razón de las fuentes que se usan para construir los productos de cada tipo de verdad para el caso colombiano. Aunque muchos otros factores nutren la posibilidad de diferenciar la verdad judicial y la verdad histórica, este artículo muestra que el uso de fuentes diferentes no es uno de ellos. También contribuyen a demostrar que estas verdades se sobreponen y que habitan todo el escenario transicional. Aunque los productos finales de verdad judicial y verdad histórica son un objeto en sí mismo y no la simple sumatoria de sus fuentes, no se puede desconocer la importancia de estas en la definición de la "naturaleza" del producto y el impacto de las formas jurídicas que se usan para llegar a su resultado. Ello no significa que esto suceda en todos los casos o que no existan productos de verdad histórica construidos exclusivamente a partir de fuentes extrajudiciales, o productos de verdad judicial construidos a partir de insumos netamente judiciales. Pero sí es necesario insistir en que el carácter de las fuentes de estos productos sirve para cuestionar la división absoluta entre verdad judicial y verdad histórica y hacer más compleja así la discusión alrededor del tipo de mecanismos diseñados para efectivamente satisfacer el derecho a la verdad, que es tan central para las transiciones, el posconflicto y la construcción de paz. Es importante ofrecer una explicación precisa sobre las lógicas de producción de los productos de verdad judicial y verdad histórica para tratar de desvirtuar las premisas sobre la insuficiencia representacional del derecho de cara a los fenómenos atroces, por un lado, y sobre el carácter irremplazable de la verdad judicial, por el otro.

\section{CONCLUSIONES}

Hasta este punto este artículo argumenta tres cosas. En primer lugar, que existe una premisa según la cual el derecho no tiene la capacidad de representación suficiente para lidiar con los eventos de atrocidad masiva, toda vez que está únicamente equipado para lidiar con el perpetrador "desviado". A partir de esta premisa $-\mathrm{y}$ de otros factores no discutidos- ha surgido el reclamo por otro tipo de mecanismos de producción de verdad que sí tengan la capacidad para capturar y representar este fenómeno colectivo. En segundo lugar, que este cargo que se le ha formulado al derecho parecería resultar en la separación 
tajante en la literatura sobre justicia transicional, tanto en la corriente crítica como en la corriente ortodoxa, entre verdad judicial y verdad histórica. Finalmente, que todo esto se traduce en un diseño institucional particular, que es el vigente y el que goza de legitimidad para el derecho internacional, en el que coexisten mecanismos judiciales y extrajudiciales de producción de verdad que son entendidos como necesarios en razón de su complementariedad para satisfacer el derecho a la verdad en las transiciones ${ }^{69}$.

En este orden de ideas, cuestionar la solidez de la división entre verdad judicial y verdad histórica es, a su vez, cuestionar los diseños institucionales internacionalmente aceptados como idóneos para las sociedades en transición y sugerir que puede haber otros que sean igualmente virtuosos. Los ejemplos mencionados en este texto prueban que no existen lugares estáticos para la producción de uno u otro tipo de verdad en la justicia transicional sino que, por el contrario, la verdad migra por todas las estaciones institucionales. Esto se demostró señalando cómo la verdad judicial es fuente de la verdad histórica y cómo lo mismo sucede con respecto a las fuentes históricas de la verdad judicial. Como se dijo, esto no cuestiona per se la pertinencia de las instituciones judiciales y extrajudiciales de la justicia transicional, sino que aporta al entendimiento de las condiciones de posibilidad del diseño institucional que está mayoritariamente aceptada por el derecho internacional para la transición y las premisas teóricas que la soportan.

Este argumento sirve para desvirtuar dos premisas. Por un lado, la premisa según la cual el derecho penal no está equipado para representar los fenómenos de atrocidad masiva por la creencia fundacional del mismo en la responsabilidad a raíz de la desviación, que se desvirtúa al demostrar que las fuentes de los mecanismos extrajudiciales de representación son mayoritaria y principalmente judiciales. En este sentido, pareciera que el derecho sí tiene una capacidad representacional enorme, pues sus productos se constituyen como las fuentes primarias y centrales para la actividad de las instituciones que buscan la verdad extrajudicial. Además, lo aquí propuesto contribuye a desvirtuar una de las premisas centrales del giro punitivo en el movimiento de derechos humanos: aquella según la cual la verdad histórica no tiene la capacidad de reemplazar a la verdad judicial. Aunque en términos de consecuencias jurídicas la verdad judicial es efectivamente irremplazable, pues la verdad histórica no tendría competencia para castigar judicialmente a los perpetradores por asignación de responsabilidades individuales, es pertinente preguntarnos si aquello que dota de poder al producto judicial mantiene su estatus si se encuentra que está, en buena parte, construido por fuentes extrajudiciales.

69 Véase Corte IDH. Caso Zambrano, op. cit.; Caso Masacres de El Mozote y lugares aledaños vs. El Salvador. Fondo, Reparaciones y Costas. Sentencia del 25 de octubre de 2012, Serie $\mathrm{C}, \mathrm{n}^{\circ}{ }^{\circ} 252$, párr. 298. Acá solamente se sugiere que esto tiene un efecto en el diseño institucional. No significa que no haya un sinnúmero de factores que lo influyan. 


\section{BIBLIOGRAFÍA}

Arendt, H y Jaspers, K. Correspondence 1926-1969, Nueva York: Harcourt Brace Jovanovich, 1992.

Centro Nacional de Memoria Histórica. La Rochela: memorias de un crimen contra la justicia. Bogotá: Publicaciones Semana, 2010. Disponible en: http://centrodememoriahistorica.gov.co/la-rochela-memorias-de-un-crimen-contra-la-justicia/.

Centro Nacional de Memoria Histórica. ¿Verdad judicial o verdad histórica? Bogotá: Publicaciones Semana, 2012. Disponible en: http://centrodememoriahistorica.gov.co/ justicia-y-paz/.

Centro Nacional de Memoria Histórica. Justicia y Paz: Los silencios y los olvidos de la verdad. Bogotá: Centro de Memoria Histórica, 2014. Disponible en: http://www.centrodememoriahistorica.gov.co/descargas/informes2012/silencios_justicia.pdf.

Campbell, C. y Ní Aoláin, F. The Paradox of Transitions in Liberal Democracies, Human Rights Quarterly, 27, 1, 2005, 172-213.

Conen, S. States of Denial: Knowing About Atrocities and Suffering. Cambridge: Polity Press, 2001.

Corte Constitucional de Colombia. C-017 de 2018. Sentencia del 21 de marzo. Bogotá, 2018.

Comisión Interamericana de Derechos Humanos. Comunicado de Prensa 48/12. Washington: OAS in Publication Data, 2012. Disponible en: http://www.oas.org/es/cidh/prensa/ comunicados/2012/comunicados_2012.asp.

Comisión Interamericana de Derechos Humanos. El Derecho a la verdad en América, Washington: OAS in Publication Data, 2012. Disponible en: http://www.oas.org/es/cidh/ informes/pdfs/Derecho-Verdad-es.pdf.

Corte Interamericana de Derechos Humanos. Caso Barrios Altos vs Perú. Sentencia del 14 de marzo (Fondo, reparaciones y costas). San José de Costa Rica, 2001. Disponible en: https://www.corteidh.or.cr/docs/casos/articulos/Seriec_75_esp.pdf.

Corte Interamericana de Derechos Humanos. Caso La Cantúa vs Perú. Sentencia del 29 de noviembre. (Fondo, reparaciones y costas). San José de Costa Rica, 2006. Disponible en: https://www.corteidh.or.cr/docs/casos/articulos/seriec_162_esp.pdf.

Corte Interamericana de Derechos Humanos. Caso Chitay Nech y Otros vs. Guatemala. Sentencia del 25 de mayo. (Excepciones preliminares, fondo, reparaciones y costas). San José de Costa Rica, 2010. Disponible en: https://www.corteidh.or.cr/docs/casos/ articulos/seriec_212_esp.pdf.

Corte Interamericana de Derechos Humanos. Caso José Miguel Gudiel Álvarez y otros vs. Guatemala. Sentencia del 20 de noviembre. (Fondo, reparaciones y costas). San José de Costa Rica, 2012. Disponible en: https://www.corteidh.or.cr/docs/casos/articulos/ seriec_253_ing.pdf.

Corte Interamericana de Derechos Humanos. Caso Vásquez Durand y otros vs. Ecuador. Sentencia de 15 de febrero. (Excepciones Preliminares, Fondo, Reparaciones y Costas). 
San José de Costa Rica, 2017. Disponible en: https://www.corteidh.or.cr/docs/casos/ articulos/seriec_332_esp.pdf

Daly, E. Truth Skepticism: An Inquiry into the Value of Truth in Times of Transition International Journal of Transitional Justice, 2, 1, 2008, 23-41.

De Roux, F. La audacia de la paz imperfecta, Bogotá: Planeta, 2018.

Declaración Universal de Derechos Humanos 1948. Disponible en: http://www.un.org/ es/universal-declaration-human-rights/.

Engle, K. Anti-Impunity and the Turn to Criminal Law in Human Rights, Cornell Law Review, 100, 5, 2015, 1069-1127.

Felman, S. The Juridical Unconscious: Trials and Traumas in The Twentieth Century, Londres: Harvard University Press, 2002.

Furedi, F. Therapy Culture: Cultivating Vulnerability in an Uncertain Age. London: Routledge, 2004.

Gobierno de Colombia y Fuerzas Armadas Revolucionarias del Colombia. Acuerdo Final para la Terminación del Conflicto Armado y la Construcción de una Paz Estable y Duradera. Bogotá, Colombia, 2016. Disponible en: https://www.cancilleria.gov.co/sites/ default/files/Fotos2016/12.11_1.2016nuevoacuerdofinal.pdf.

Hayner, P. Unspeakable Truths, Nueva York: Routledge, 2011.

McEvoy, K. Beyond Legalism: Towards a Thicker Understanding of Transitional Justice, Journal of Law and Society, 34, 4, 2007, 411-440.

Meister, R. After Evil. A Politics of Human Rights. Nueva York: Columbia University Press, 2012.

Mohamed, S. Deviance, Aspiration, and the Stories We Tell: Reconciling Mass Atrocity and the Criminal Law, Yale Law Journal, 124, 5, 2015, 1628-1689.

Moon, C. Healing Past Violence: Traumatic Assumptions and Therapeutic Interventions in War and Reconciliation, Journal of Human Rights, 8, 1, 2009, 71-91.

Moon, C. Narrating Political Reconciliation: Truth and Reconciliation in South Africa, Social and Legal Studies, 15, 2, 2006, 257-275.

Ní Aoláin, F. y Turner, C. Gender, Truth and Transition. uCLA Women's Law Journal, 16, 2007.

Orozco, I. Sobre los límites de la conciencia humanitaria: dilemas de la paz y la justicia en América Latina, Bogotá: Editorial Temis, 2005.

Orozco, I. Justicia transicional en tiempos del deber de memoria, Bogotá: Ediciones Uniandes, 2009.

Restrepo, E., y Botero, C. Estándares internacionales y procesos de transición en Colombia. En: Uprimny YePes, R. et al. ¿Justicia transicional sin transición? Verdad, justicia y reparación para Colombia, Bogotá: Ediciones Antropos, 2006, 45-108. 
SÁnchez, G. La memoria y la justicia. Palabras en entrega de Informes del Centro Nacional de Memoria Histórica (CNMH) a la Jurisdicción Especial para la Paz (JEP). Bogotá, 2017. Disponible en: http://centrodememoriahistorica.gov.co/la-memoria-y-la-justicia/

Siknink, K. The Justice Cascade: How Human Rights Prosecutions are Changing World Politics, Nueva York: W. W. Norton, 2013.

Stahn, C. La geometría de la justicia transicional: opciones de diseño institucional. En: RetTBERG, A. Entre el perdón y el paredón: preguntas y dilemas de justicia transicional, Bogotá: Ediciones Uniandes, 2005, 81-142.

Subotić, J. Bargaining Justice: A Theory of Transitional Justice Compliance. En: BuckLeYZistel, S. et al, Transitional Justice Theories, Nueva York: Routledge, 2014, 127-143.

Teitel, R. Transitional Justice Genealogy. Harvard Human Rights Journal, 16, 2015, 69-94.

Turner, C. Violence, Law and the Impossibility of Transitional Justice. London: Routledge, Taylor \& Francis Group, 2016.

United Nations (UN), General Assembly, a/hrc/37/65, 6 de junio de 2018. Disponible en https://www.ohchr.org/sP/HRBodies/HRC/RegularSessions/Session37/Pages/ListReports.aspx

United Nations (UN). Guidance Note of the Secretary-General. United Nations Approach to Transitional Justice, March 2010. Disponible en: https://www.un.org/ruleoflaw/files/ TJ_Guidance_Note_March_2010FInAL.pdf.

United Nations (UN). The Rule of Law and Transitional Justice in Conflict and Post-conflict Societies: Report of the Secretary-General, 2004. Disponible en: https://www.un.org/ ruleoflaw/blog/document/the-rule-of-law-and-transitional-justice-in-conflict-and-postconflict-societies-report-of-the-secretary-general/

Uprimny, R., y SAFFon, M. Derecho a la verdad: límites y potencialidades de la verdad judicial. En: UpRIMnY YePES, R. et al. ¿Justicia transicional sin transición? Verdad, justicia y reparación para Colombia, Bogotá: Ediciones Antropos, 2006, 139-172.

Weinstein, H. Editorial Note: The Myth of Closure, the Illusion of Reconciliation: Final Thoughts on Five Years as Co-Editor-in-Chief, International Journal of Transitional Justice, 6, 2011.

Wilson, R. The Politics of Truth and Reconciliation in South Africa: Legitimising the Post-Apartheid State, Cambridge: Cambridge University Press, 2001. 